\title{
Impact of aerosol particle sources on optical properties in urban, regional and remote areas in the north-western Mediterranean
}

Marina Ealo et al.

Correspondence to: Marina Ealo (marina.ealo@idaea.csic.es)

The copyright of individual parts of the supplement might differ from the CC BY 3.0 License. 


\begin{tabular}{llll}
\hline Parameters & BCN & MSY & MSA \\
\hline$\sigma_{\text {sp }}$ & - & $2010-2014$ & $2011-2014$ \\
$\sigma_{\text {ap }}$ & $2009-2014$ & $2010-2014$ & $2011-2014$ \\
Species concentration & $2004-2014$ & $2004-2014$ & $2010-2014$
\end{tabular}

Table S1. Study period considered for the measured parameters ( $\sigma_{\mathrm{sp}}, \sigma_{\mathrm{sp}}$ and chemical species concentration) at the three 5 different sites (BCN, MSY and MSA). 
a) $\mathrm{BCN}$

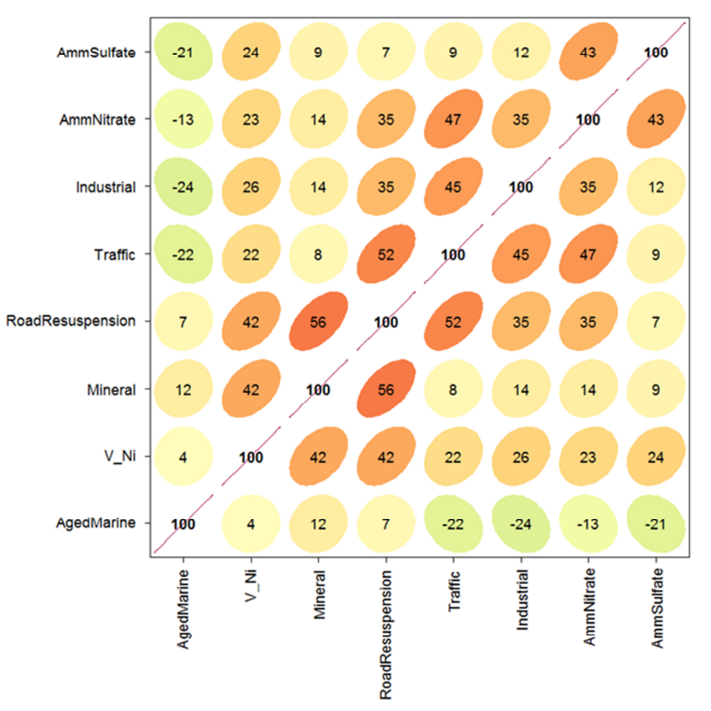

b) MSY

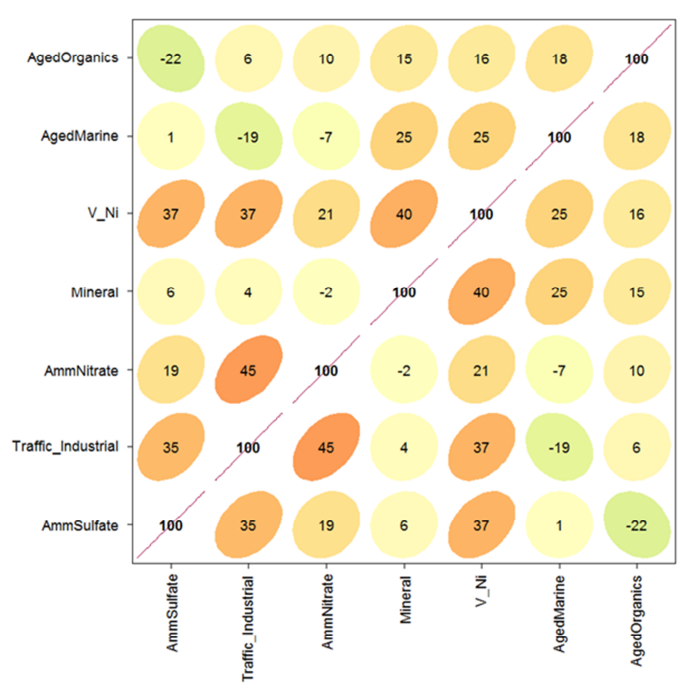

c) MSA

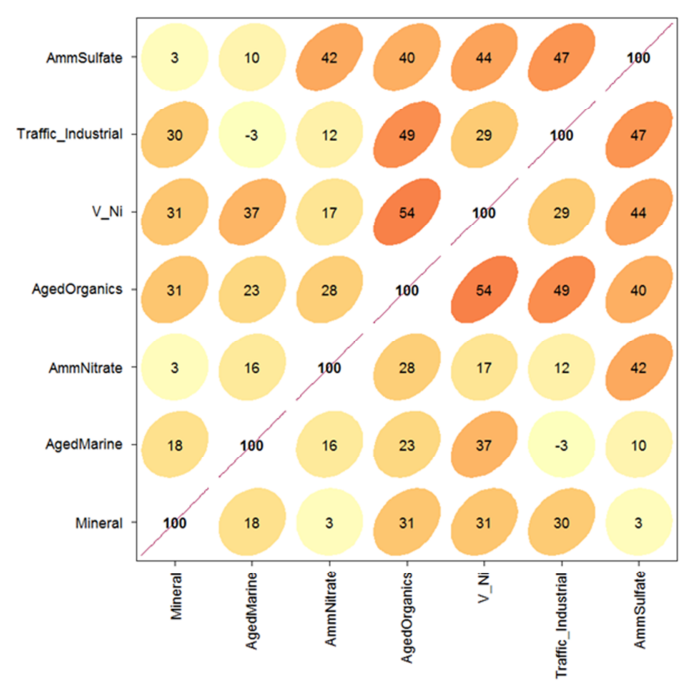

Figure S1. Correlation matrix between pairs of aerosol sources obtained by means of the PMF model at a) BCN, b) MSY and c) MSA. The correlation is coded by shape and colour for better visualization, lower correlations are represented by circles and lighter colours whereas higher correlations are represented by ellipses and darker colours. 

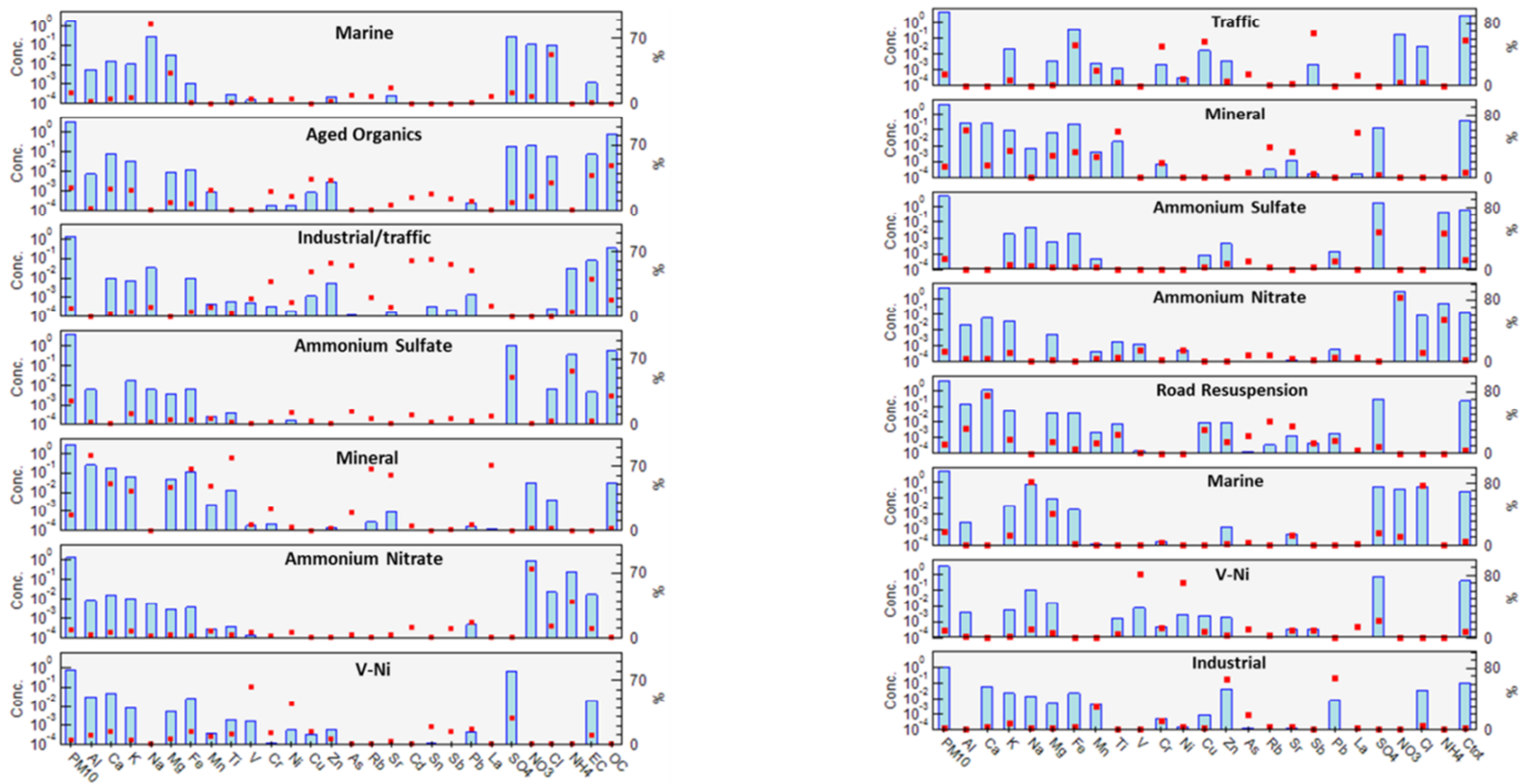

Figure S2. Source chemical profiles obtained by means of the PMF model at MSY and BCN for the period 2004-2014 (Pandolfi et al., 2016). 